\title{
Behaviour of cement concrete at high temperature
}

\author{
I. HAGER* \\ Institute of Building Materials and Structures, Cracow University of Technology, 24 Warszawska St., 31-155 Kraków, Poland
}

\begin{abstract}
The paper presents the impact of high temperature on cement concrete. The presented data have been selected both from the author's most recent research and the published literature in order to provide a brief outline of the subject. The effect of a high temperature on concrete covers changes taking place in cement paste, aggregates, as well as the interaction of these two constituents, that result in changes of mechanical and physical characteristics of concrete. This paper presents the effects of a high temperature on selected physical properties of concrete, including colour change, thermal strain, thermal strains under load, and transient thermal strains. In addition, changes to mechanical properties are discussed: stress-strain relationship, compressive strength, and modulus of elasticity. Moreover, the phenomenon of explosive spalling and the main factors that affect its extent are analysed in light of the most recent research.
\end{abstract}

Key words: concrete, high temperature, fire damage, thermal strain, transient thermal strain, hot tested mechanical properties, residual properties.

\section{Introduction}

Interest in the behaviour of concrete at a high temperature mainly results from the many cases of fires taking place in buildings, high-rise buildings, tunnels, and drilling platform structures. During a fire, the temperature may reach up to $1100^{\circ} \mathrm{C}$ in buildings and even up to $1350^{\circ} \mathrm{C}$ in tunnels, leading to severe damage in a concrete structure [1]. However, in some special cases, even much lower temperature, may cause explosive destruction of concrete, thus endangering the bearing capacity of the concrete element. Nevertheless, concrete is considered a construction material that satisfactorily preserves its properties at high temperature. Owing to concrete's fairly low coefficient of thermal conductivity, the movement of heat through concrete is slow, and thus reinforced steel, which is sensitive to high temperature, is protected for a relatively long period of time. When concrete is heated under conditions of fire, the increase in temperature in the deeper layers of the material is progressive, but because this process is slow, significant temperature gradients are produced between the concrete member's surface and core inducing additional damage to the element. Fundamental issues related to the impact of high temperature on concrete involve identification of the complex changes that take place in concrete while heated. This concerns both the physical and chemical changes taking place in the cement matrix, as well as the phenomena involved in mass movement (gases and liquids). The analysis is complicated due to the fact that cement concrete is a composite consisting of two substantially different constituents: cement paste and aggregates. The effects of the various changes taking place in heated concrete are the alterations of its physical, thermal, and mechanical properties. Research has demonstrated [1, 2], that changes in the strength of concrete as a function of temperature are related to, inter alia, concrete composition the type of aggregate used, the water/cement ratio, the presence of pozzolana additives, etc. Important factors are also the rate of heating and the time of concrete exposure to high temperature. The increase in temperature results in water evaporation, C-S-H gel dehydration, calcium hydroxide and calcium aluminates decomposition, etc. Along with the increase in temperature, changes in the aggregate take place. Due to those changes, concrete strength and modulus of elasticity gradually decreases, and when the temperature exceeds ca. $300^{\circ} \mathrm{C}$, the decline in strength becomes more rapid. When the $500^{\circ} \mathrm{C}$ threshold is passed, the compressive strength of concrete usually drops by $50 \%$ to $60 \%$, and the concrete is considered fully damaged. The Eurocode method of calculating the loadbearing capacity of reinforced concrete members subjected to a fire is based on this assumption. In the $500^{\circ} \mathrm{C}$ isotherm method, sections of concrete surface where the temperature had exceeded $500^{\circ} \mathrm{C}$ are omitted from the calculations [3].

\section{Impact of temperature effect on concrete microstructure}

2.1. Cement paste. The heating of cement paste results in drying. Water gradually evaporates from the material. The order in which water is removed from heated concrete depends on the energy that binds the water and the solid. Thus, free water evaporates first, followed by capillary water, and finally by physically bound water. The process of removing water that is chemically bound with cement hydrates is the last to be initiated. The mechanical properties of cement paste are strongly affected by chemical bonds and cohesion forces between sheets of calcium silicate hydrate (C-S-H) gel. It is assumed that approximately $50 \%$ of cement paste strength comes from cohesion forces (important C-S-H gel sheet area); therefore, the evaporation of water between $\mathrm{C}-\mathrm{S}$ $\mathrm{H}$ gel sheets strongly affects the mechanical properties of the cement paste [4]. However, when the cement paste is heat-

*e-mail: ihager@pk.edu.pl 
ed in moist sealed conditions, hydrothermal reactions may take place. This phenomenon, called internal autoclaving [5], may occur in large members where, due to heating, moisture is transformed into water vapour. In these conditions chemical and physical changes may take place. The process of simultaneously exposing the material to high pressures and temperature is a well-known technology in the prefabrication of concrete. This may well activate changes in the microstructure of hydrates and often increases cement paste strength. The nature of the phase changes will depend upon the mineralogical composition of the cement, its $\mathrm{C} / \mathrm{S}$ ratio (mols of lime per mol of silica; $\mathrm{CaO} / \mathrm{SiO}_{2}$ ), the amount of fine particles (quartz or silica fume), and the temperature and pressure levels that have been reached [6]. Heating the cement paste with a $\mathrm{C} / \mathrm{S}$ ratio around 1.5 to temperature above $100^{\circ} \mathrm{C}$ produces several forms of calcium silicates, in general highly porous and weak. When the $\mathrm{C} / \mathrm{S}$ ratio is close to 1.0 and the temperature is above $150^{\circ} \mathrm{C}$, a 1.5 to 1.0 tobemorite gel can form. At temperature between $180^{\circ} \mathrm{C}$ and $200^{\circ} \mathrm{C}$, other silicates such as xonolite and hillebrandite may be formed. Recently, microstructural changes of heated cement pastes have been studied by neutron diffraction [7]. This research demonstrates the temperature at which the main products of hydration of Portland cement, including portlandite, ettringite, calcite, lime, larnite, and hydrated calcium silicate (C-S-H gel), are present. During heating, ettringite decomposes first, even before the temperature reaches $100^{\circ} \mathrm{C}$. C-S-H gel dehydration is progressive and takes place from the very beginning of material heating. It is worth noting that the structure of the cement paste is partially damaged due to dehydration at the temperature of $105^{\circ} \mathrm{C}$, which is standard for the drying of materials. As soon as cement paste is heated to temperature of $500-550^{\circ} \mathrm{C}$, the portlandite content rapidly drops, as it decomposes according to the following reaction: $\mathrm{Ca}(\mathrm{OH})_{2} \rightarrow \mathrm{CaO}+\mathrm{H}_{2} \mathrm{O} \uparrow$. The portlandite decomposition reaction explains the observed increase in $\mathrm{CaO}$ content in cement paste at the temperature of approximately $550^{\circ} \mathrm{C}[5$, 7]. The $\mathrm{CaO}$ created in this reaction makes the elements made of the Portland cement practically redundant after cooling. The dehydration process of the $\mathrm{C}-\mathrm{S}-\mathrm{H}$ gel reduces its volume, which in turn increases the porosity of the cement

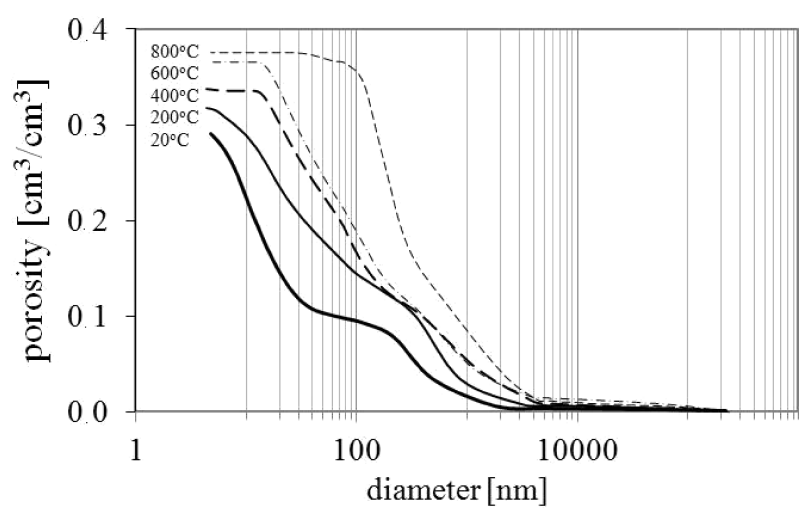

Fig. 1. Effect of heating on cumulative pore volume of Portland cement paste heated to $200^{\circ} \mathrm{C}, 400^{\circ} \mathrm{C}, 600^{\circ} \mathrm{C}$, and $800^{\circ} \mathrm{C}(\mathrm{w} / \mathrm{c}=0.6)$ matrix. Moreover, during heating, the cement paste experiences a slight expansion up to temperature of approximately $200^{\circ} \mathrm{C}[5,6,8,9]$ although the intense shrinkage begins as soon as this temperature is exceeded. This significantly contributes to the porosity evolution of the cement paste. Due to heating total pore volume increases, as does the average pore size see Fig. 1.

2.2. Aggregate. Aggregates occupy $70-80 \%$ of the volume of concrete and thus heavily influence its thermal behaviour. The term "thermal stability of aggregates" is employed [2] to describe aggregates effect on concrete performance at high temperature. "Thermally stable" aggregates are characterized by chemical and physical stability at high temperature, which is determined by dilatometric, as well as thermogravimetric, and differential thermal tests. Considering concrete behaviour at high temperature, a suitable aggregate would be one with a low thermal strains coefficient as well as negligible residual strains. Another aspect necessary to be considered is the absence of peaks along the differential thermal analysis (DTA) and thermogravimetric analysis (TGA) curves, which indicates no weight loss and no thermal reaction. Mineralogical composition determines aggregate thermal strains, since all minerals differ in their thermal expansion properties. The type of minerals governs the chemical and physical changes that take place during heating. For example: quartz aggregates and sands change at $574{ }^{\circ} \mathrm{C}$ due to the $\beta-\alpha$ quartz inversion. This physical transformation involves a volumetric increase clearly visible on DTA curves in Fig. 2 [2]. The carbonate stones (limestone and dolomite) are stable up to $600^{\circ} \mathrm{C}$. At higher temperature, carbonate aggregate decomposes into $\mathrm{CaO}$ and $\mathrm{CO}_{2}\left(700^{\circ} \mathrm{C}\right)$. Additionally, the $\mathrm{CaO}$ formed during decarbonation may hydrate when cooling, with a consequent $44 \%$ expansion. The polymineralic stones may be prone to the disintegration that results from the thermal incompatibility of its components. For those stones differences in thermal strain can cause inter-crystalline stresses and failure. The further heating of aggregate leads to its melting. The melting temperature vary along the mineralogical composition, for most igneous rock it is above $1000^{\circ} \mathrm{C}$. The melting temperature of granites is $1210-1250^{\circ} \mathrm{C}$, while basalts melt at $1050^{\circ} \mathrm{C}$, which is accompanied by gas release and expansion.

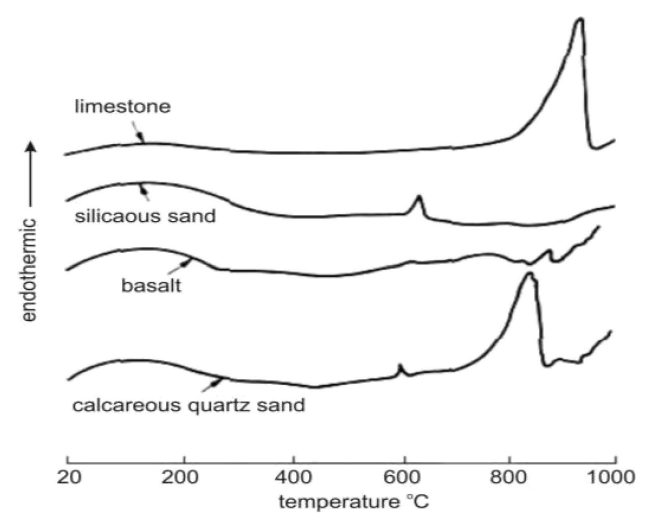

Fig. 2. DTA of four types of aggregates, measured during heating at $10^{\circ} \mathrm{C} / \mathrm{min}$ 
2.3. Cement paste and aggregate interaction in concrete during heating. The heating of concrete makes its aggregate volume grow, and at the same time it causes the contraction of the cement paste which surrounds it. As a result, the cement paste-aggregate bond is the weakest point in heated cementitious material. To a large extent, damage to concrete is caused by cracking, which occurs arising due to mismatched thermal strains between the coarse aggregates and the matrix. Figure 3 shows an example of thermally damaged concrete, which is made of silico-calcareous aggregates, and heated to $600^{\circ} \mathrm{C}$ [9]. The SEM photo shows cracks crossing the cement paste and proceeding though the interfacial transition zone. Also, cracks passing through siliceous aggregate are present, indicating the tendency of some siliceous aggregates to break up at $350^{\circ} \mathrm{C}$ [2]. Table 1 lists the changes that take place concrete components: cement paste and aggregates. The changes are listed according to the temperature of their occurrence and were compiled on the basis of [2,5] and [7].

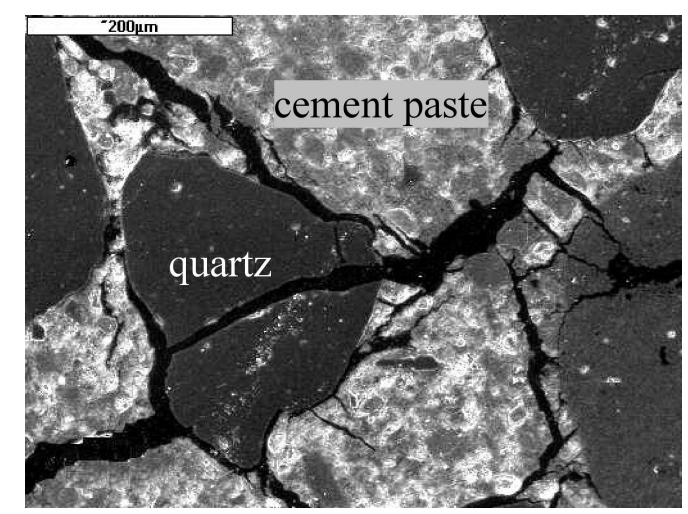

Fig. 3. The microstructure of concrete heated to $600^{\circ} \mathrm{C}(\mathrm{SEM}, 50 \times)$, concrete based on silico-calcareous aggregates, $f_{c}=75 \mathrm{MPa}$

Table 1

The list of changes taking place in concrete during heating

\begin{tabular}{|c|c|}
\hline $\begin{array}{c}\text { Temperature } \\
\text { range }\end{array}$ & Changes \\
\hline $20-200^{\circ} \mathrm{C}$ & $\begin{array}{l}\text { slow capillary water loss and reduction in cohesive } \\
\quad \text { forces as water expands; } \\
80-150^{\circ} \mathrm{C} \text { ettringite dehydration; } \\
\mathrm{C}-\mathrm{S}-\mathrm{H} \text { gel dehydration; } \\
150-170^{\circ} \mathrm{C} \text { gypsum decomposition }\left(\mathrm{CaSO}_{4} \cdot 2 \mathrm{H}_{2} \mathrm{O}\right) \text {; } \\
\text { physically bound water loss; }\end{array}$ \\
\hline $300-400^{\circ} \mathrm{C}$ & $\begin{array}{l}\text { approx. } 350^{\circ} \mathrm{C} \text { break up of some siliceous aggregates } \\
\quad \text { (flint); } \\
374^{\circ} \mathrm{C} \text { critical temperature of water; }\end{array}$ \\
\hline $400-500^{\circ} \mathrm{C}$ & $\begin{array}{l}460-540^{\circ} \mathrm{C} \text { portlandite decomposition } \\
\mathrm{Ca}(\mathrm{OH})_{2} \rightarrow \mathrm{CaO}+\mathrm{H}_{2} \mathrm{O}\end{array}$ \\
\hline $500-600^{\circ} \mathrm{C}$ & $\begin{array}{l}573^{\circ} \mathrm{C} \text { quartz phase change } \beta-\alpha \text { in aggregates and } \\
\text { sands; }\end{array}$ \\
\hline $600-800^{\circ} \mathrm{C}$ & $\begin{array}{l}\text { second phase of the C-S-H decomposition, formation } \\
\text { of } \beta-C_{2} \mathrm{~S} \text {; }\end{array}$ \\
\hline $800-1000^{\circ} \mathrm{C}$ & $\begin{array}{l}840^{\circ} \mathrm{C} \text { dolomite decomposition; } \\
930-960^{\circ} \mathrm{C} \text { calcite decomposition } \\
\quad \mathrm{CaCO}_{3} \rightarrow \mathrm{CaO}+\mathrm{CO}_{2} \text {, carbon dioxide release; } \\
\text { ceramic binding initiation which replaces hydraulic } \\
\quad \text { bonds; }\end{array}$ \\
\hline $1000-1200^{\circ} \mathrm{C}$ & $1050^{\circ} \mathrm{C}$ basalt melting; \\
\hline $1300^{\circ} \mathrm{C}$ & total decomposition of concrete, melting. \\
\hline
\end{tabular}

\section{Physical and mechanical properties changes of heated concrete}

3.1. Colour change of heated concrete. It is generally agreed $[10,11]$ that when heated to between $300^{\circ} \mathrm{C}$ and $600^{\circ} \mathrm{C}$ concrete containing siliceous aggregates will turn red; between $600^{\circ} \mathrm{C}$ and $900^{\circ} \mathrm{C}$, whitish-grey; and between $900^{\circ} \mathrm{C}$ and $1000^{\circ} \mathrm{C}$, a buff colour is present. The colour change of heated concrete results principally from the gradual water removal and dehydration of the cement paste, but also transformations occurring within the aggregate [10-12]. The most intense colour change, the appearance of red colouration, is observed for siliceous riverbed aggregates containing iron. This colouration is caused by the oxidation of mineral components [10-12]. While siliceous aggregates turn red when heated, the aggregates containing calcium carbonate get whitish. Due to calcination process $\mathrm{CaCO}_{3}$ turns to lime and give pale shades of white and grey.

In general two approaches can be adopted when the colour change of concrete is analysed [12]. First, the external surface of the element can be examined. This involves the observation of an element's outer walls (in particular, the cement paste). The other possibility is to observe the surface with visible aggregates (sample cored or sawn out from the element). When it is necessary to evaluate the condition of concrete after a fire, colour change is a physical property of concrete that can be used as an assessment method [10,11]. Recently, the author has proposed a technique allowing for the evaluation of heated concrete colour change [12]. In this method, pictures are taken with a general-purpose flatbed scanner. The use of a flatbed scanner allows for images to be taken under constant light conditions. The digital image is then analysed using the image analysis software package Scion Image (version 4.0.3, Scion Corporation ${ }^{\circledR}$, USA). With its use the digital image spitted into three RGB colour components, red, green, and blue, which are then presented as a histogram using counts of pixel intensity (all pixels are represented by RGB values ranging from 0 to 255). The analysis involves a normalisation process where values corresponding to the number of pixels with a specified intensity are divided by the total number of pixels in a given image. Histogram normalisation makes the comparison of images with different pixel counts possible. In Fig. 4, the colour changes of heated concrete made with the riverbed aggregates are presented [12]. Moreover, an example of normalised histograms of the red component's intensity values obtained for heated concrete is presented in Fig. 5. Histograms from laboratory-heated concrete provide a scale, which may be used to evaluate the temperature actually reached by concrete in a structure affected by fire [12].

\subsection{Thermal strain, thermal strain under load and tran-} sient thermal strain of concrete Concrete, as with most building materials, expands during heating. The thermal strain $\left(\varepsilon_{t h}\right)$ of heated concrete can be measured, and by this measurement the coefficient of thermal expansion can be determined. However, the range in which this coefficient can be 


\section{Hager}

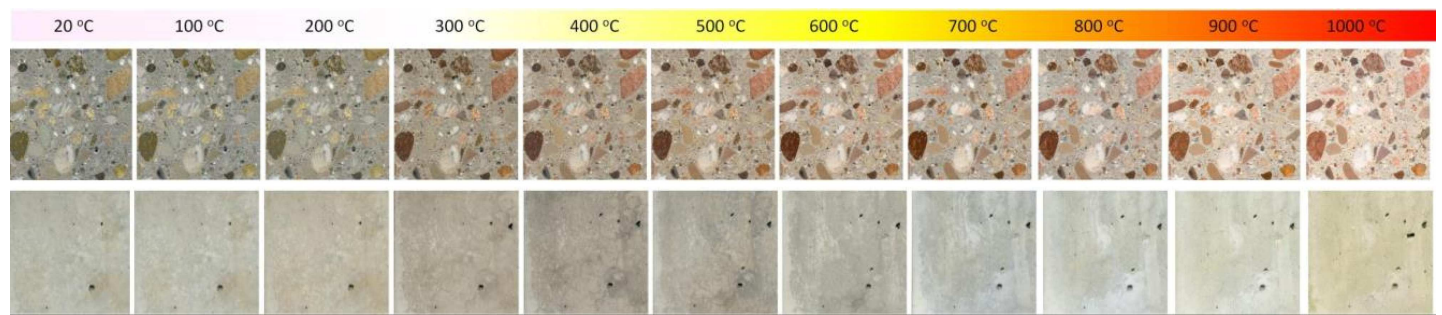

Fig. 4. Colour change of heated concrete: surface with exposed aggregates and external surface of the concrete specimen $\left(\mathrm{HPC}, \mathrm{f}_{c 20^{\circ} C}=\right.$ $97 \mathrm{MPa})$

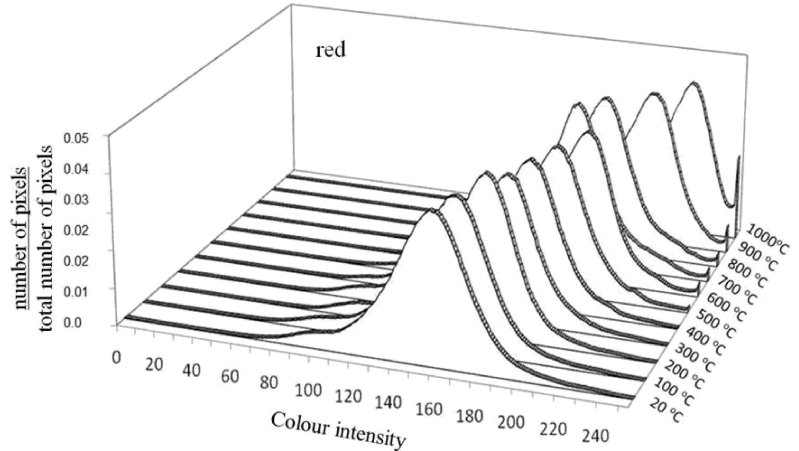

Fig. 5. The normalised histograms of the Red component intensity values obtained for heated concrete (surface with exposed aggregates) in the range of temperature from $20^{\circ} \mathrm{C}$ to $1000^{\circ} \mathrm{C}$, (HPC,

$$
\left.\mathrm{f}_{c 20^{\circ} \mathrm{C}}=97 \mathrm{MPa}\right)
$$

considered constant is limited due to the non-linear character of the $\varepsilon_{t h}$ curve. This non-linearity is mainly due to the appearance of cracks that are the result of thermal strain incompatibility between the shrinking cement paste and the expanding aggregates. The main factor dominating the extent of concrete expansion is the mineralogical character of the aggregate. For example concrete containing basalt aggregates has a lower thermal expansion coefficient than concrete containing calcareous aggregates. As it was mentioned in Subsec. 2.2, thermally stable aggregates with low thermal expansion are favourable for the reasons of durability in fire conditions.

In Fig. 9, the results of measurements of thermal strain of two HPC concretes made with silico-calcareous aggregates and calcareous aggregates are shown [9]. The experiments have been performed on cylindrical samples (diameter 100 $\mathrm{mm}$, height $300 \mathrm{~mm}$ ). The technique of measuring thermal strain and thermal strain under load was inspired by research conducted by Khoury et al. [8], and Diederichs et al. [13], as well as RILEM (Réunion Internationale des Laboratoires et Experts des Matériaux) guidelines concerning the measurement of thermal strain in concrete [14]. This measurement system has previously been described in detail $[9,15]$. It allows for the measurement of thermal strain and thermal strain under load on concrete samples. Thermal strain of concretes with silico-calcareous aggregates significantly exceeds those obtained for concrete made with calcareous aggregate (see Fig. 6). At a temperature of $600^{\circ} \mathrm{C}$, the strain value is twice as high than those measured for calcareous aggregates reaching up to $20[\mathrm{~mm} / \mathrm{m}]$. This fact should be associated with the higher thermal expansion coefficient of siliceous aggre- gates. In addition, the phase transformation of quartz, which occurs at $573^{\circ} \mathrm{C}$, is accompanied by a significant increase in aggregate volume. Higher expansion, as well as significantly higher residual strain after cooling down, was observed for concrete with siliceous aggregates (Fig. 6), which was the result of an important number of cracks visible on the surface of samples (Fig. 7 from [9]). The determinant character of the aggregates controlling the thermal strain of concrete was also observed when thermal strains of different types of concretes made with the same type of aggregates were compared. The thermal strains measured on ordinary concrete (OC) and two HPCs made with the same type and content of aggregate (69\% in the case of OC and $71 \%$ in the case of two HPCs) were almost identical, despite differences in their composition, i.e. different water cement ratios w/c, different types of cement used [9].

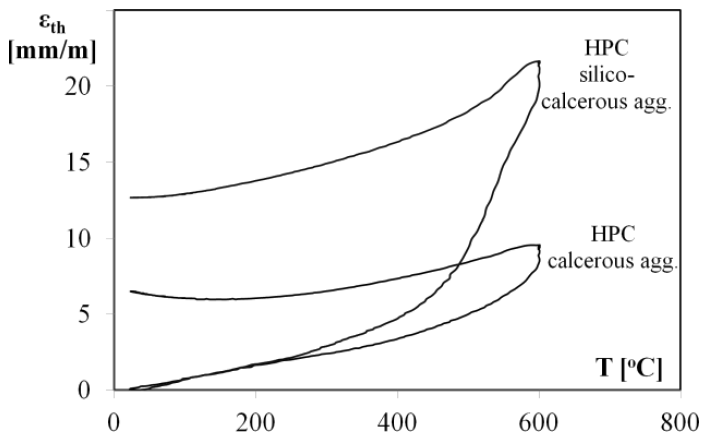

Fig. 6. Thermal strains of two HPCs containing silico-calcareous, and calcareous aggregates. Samples heated to $600^{\circ} \mathrm{C}$ and cooled down to the room temperature

a)

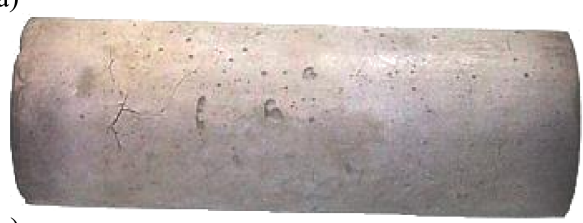

b)

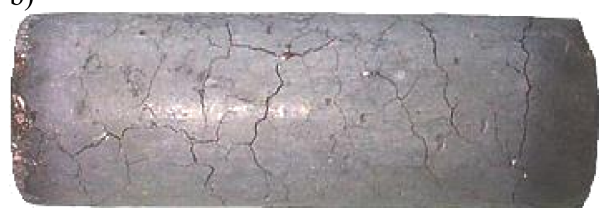

Fig. 7. Visible cracks on the surface of specimens after heating to $600^{\circ} \mathrm{C}$, a) HPC with calcareous, and b) HPC with silico-calcareous aggregates 
Thermal strains under load of concrete are measured when concrete is heated under a constant applied compressive load. The load is applied prior to heating, and strain measurement starts when heating begins (initial elastic strain subtraction). The load level applied $(\alpha)$ is usually expressed as a percentage of the compressive strength of tested concrete; the load level is maintained at a constant level during heating. The load level remains the predominant factor affecting the development of those strains. Fig. 8 presents the thermal strains under compressive load of $\alpha=20 \%$ and $40 \%$ for HPC made with calcareous aggregates [9]. Absolute values of the deformation of concrete subjected to both thermal and mechanical loads are smaller than the thermal strains. In particular, when the load is of $20 \% f_{c}$, those deformations are close to zero (see Fig. 8). By increasing the load from $20 \%$ to $40 \%$ $f_{c}$, strains measured during heating are of opposite direction than thermal expansion. Strain in a concrete element $(\varepsilon)$ simultaneously exposed to mechanical and thermal load combines mechanical strain, thermal strain, creep strain and the less known transient thermal strain (TTS) which appears during the non-stationary heating of concrete under mechanical load [8]:

$$
\varepsilon=\varepsilon_{s}+\varepsilon_{t h}+\varepsilon_{t r}+\varepsilon_{c r e e p}
$$

where: $\varepsilon_{s}$ is the instantaneous stress-dependent strain, $\varepsilon_{t h}$ is the thermal strain, $\varepsilon_{t r}$ is the transient thermal strain, and $\varepsilon_{\text {creep }}$ is the creep strain. Assuming that classical material creep is negligible due to the relatively short duration of the experiment (around 10 hours), thermal strain $\left(\varepsilon_{t h}\right)$ and thermal strain under load $(\varepsilon)$ measurements allow the transient thermal strain $\left(\varepsilon_{t r}\right)$ to be determined. The transient thermal strain curve is obtained by subtracting the values of thermal strains from the thermal strains under load measured during non-stationary heating.

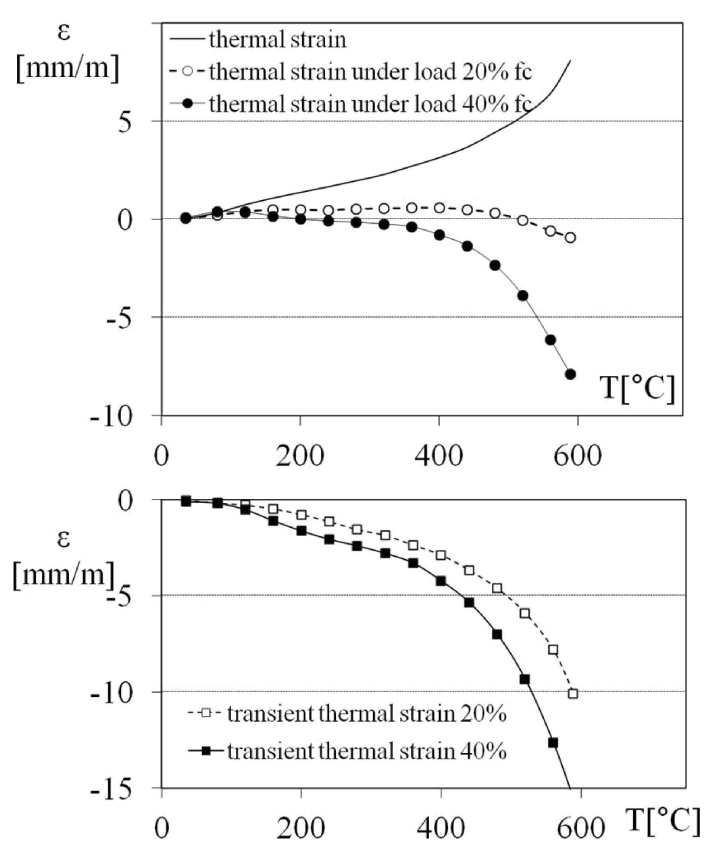

Fig. 8. Thermal strains, thermal strains under load and transient thermal strains of HPC concrete
Recent experimental studies of transient thermal strain on HPC [9, 16, 17] examined the influences of several parameters: load level, original compressive strength of concrete, the nature of aggregate, presence of fibres, the heating scenario, and initial moisture content. As the results indicated, water in cement paste plays a substantial role in development and extent of this phenomenon. It was observed that transient thermal strain activation starts with water migration and cement paste dehydration. As a result, the pre-heating of concrete samples at various temperature prior to testing significantly alters its development. It was also observed that transient thermal strain only appears during the first heating cycle [8, $9,15]$.

3.3. Stress strain relationship, compressive strength, and modulus of elasticity. Changes in mechanical properties that occur during heating are the result of changes taking place in concrete. Those material factors include physico-chemical changes in cement paste and aggregates as well as the incompatibilities between them listed in Table 1. Other factors affecting the material damage level are as follows: heating rate, maximum temperature, time of exposure to temperature, load applied during heating, moisture content of the material, etc. The testing method itself has an important influence on the evaluation of the properties of heated material. The most common way to study the influence of high temperature on the properties of concrete is to expose the material to high temperature, cool it down to room temperature, and then carry out testing, such as compression or tensile tests. However, this method gives the "post fire" or "post exposure to the high temperature" properties of concrete. Nevertheless, one must consider that the most appropriate procedure to test the mechanical properties at high temperature is to determine the properties of material at elevated temperature (tested "hot"). In order to carry out this kind of observation, special high temperature test equipment was developed [9]. This test device performs compressive tests, but can also be adapted to direct tensile tests at "hot" stage accompanied with the strain measurement. Additionally, this experimental set-up allows the thermal strain of concrete during heating to be measured, either under load (thermal strain under load) or without sample loading (free thermal strains). As it was shown in [18], the tested "hot" properties are higher than the residual ones (see Fig. 9). The testing of material at the "hot" stage is concerned with the determination of a material's properties under fire conditions, while testing after cooling gives the residual values corresponding to the post-fire performance of concrete. The lower values of residual mechanical properties are attributed to supplementary damage due to additional stresses caused by cooling. The extent of stresses depends on, among other things, the rate of cooling. As a result, rapid cooling or quenching results in higher levels of damage. The extent of damage done during the cooling phase may increase when moisture is absorbed from the surroundings. Rehydration of $\mathrm{CaO}$ - the product of portlandite and/or calcium carbonate decomposition - results in a $44 \%$ increase of volume, causing the development of cracks. 


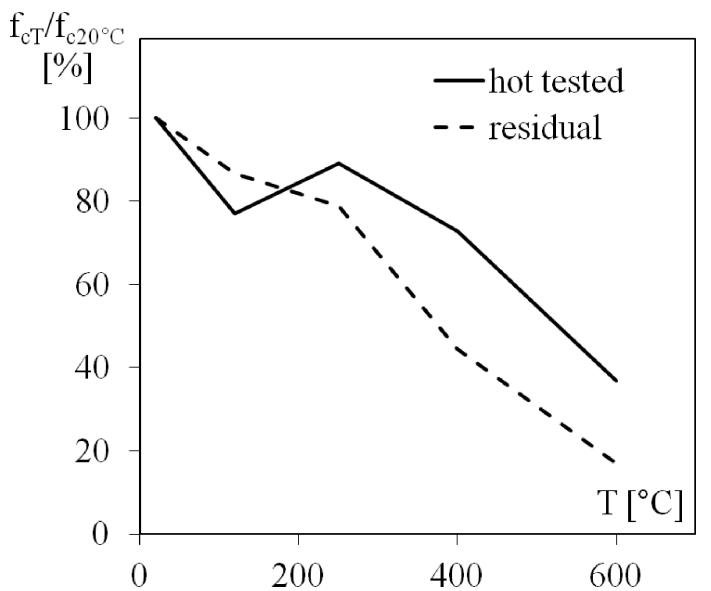

Fig. 9. Relative compressive strength as a function of temperature for HPC "hot" and residual behaviour (HPC, $0.9 \mathrm{~kg} / \mathrm{m}^{3}$ fibres,

$$
\left.\mathrm{f}_{c 20^{\circ} \mathrm{C}}=91 \mathrm{MPa}\right)
$$

To demonstrate the impact of the temperature on concrete, the following are presented below: the stress-strain relationship, the compressive strength $\left(f_{c}\right)$, and the modulus of elasticity (E) of three concretes. In addition, the relative values of $f_{c}$ and $\mathrm{E}$ are also discussed in this section. Relative values are defined as a percentage of unheated concrete properties. It is important to mention that all tests were performed using the same testing device that was used for the determination of thermal strain (chapter 3.2) on concrete samples heated to the target temperature and loaded to failure at "hot" stage. Tested "hot" properties were determined on material heated at a constant rate of $1^{\circ} \mathrm{C} / \mathrm{min}$. After the test temperature was reached, it was maintained at a constant level for 2 hours at $120^{\circ} \mathrm{C}$ and 1 hour at $250^{\circ} \mathrm{C}, 400^{\circ} \mathrm{C}$ and $600^{\circ} \mathrm{C}$ in order to stabilize the temperature inside the sample and minimize the thermal gradients within the specimen. The $120^{\circ} \mathrm{C}$ temperature was stabilised for a longer time due to its slower heat propagation caused by the high specific heat of concrete at temperature around $100^{\circ} \mathrm{C}$. In the presented research [19], concretes were made from calcareous aggregates and CEM I 52.5R cement. The quantitative and qualitative composition of all HPCs examined were the same, with the exception of the amounts of water used. Thanks to this, concretes with three water/cement ratios were obtained differentiated in terms of compressive strength. The compositions were as follows: cement $-377 \mathrm{~kg} / \mathrm{m}^{3}$, quartz sand $432 \mathrm{~kg} / \mathrm{m}^{3}$, calcareous aggregates: $0 / 5 \mathrm{~mm}-439 \mathrm{~kg} / \mathrm{m}^{3}, 5 / 12.5 \mathrm{~mm}-488 \mathrm{~kg} / \mathrm{m}^{3}, 12.5 / 20$ $\mathrm{mm}-561 \mathrm{~kg} / \mathrm{m}^{3}$, silica fume $-37.8 \mathrm{~kg} / \mathrm{m}^{3}$, high-range waterreducing admixture $-12.5 \mathrm{~kg} / \mathrm{m}^{3}$ and the water content: 124 $\mathrm{kg} / \mathrm{m}^{3}, 150 \mathrm{~kg} / \mathrm{m}^{3}$ and $189 \mathrm{~kg} / \mathrm{m}^{3}$ for concretes with $\mathrm{w} / \mathrm{c}=$ $0.3,0.4$, and 0.5 , respectively.

In Fig. 10, the stress-strain curves of three heated concretes are presented [19]. It can be observed that, with the increase in temperature, the material becomes more deformable. The increase in temperature results in a reduction in the slope of $\sigma(\varepsilon)$ curves. While the values of modulus of elasticity decrease steadily, the ultimate stresses and compressive strength results show a more complex course for all three hot-tested concretes (Figs. 11 and 12, both from [19]). We can distinguish three consecutive phases in the compressive strength evolution. The hypotheses concerning the occurrence of these phases are presented below.

In phase I, between $20^{\circ} \mathrm{C}$ and $120^{\circ} \mathrm{C}$, we notice a decrease of compressive strength values by about 20-30\% for all three concretes that tested "hot" (Figs. 11 and 12 ). This weakening was also observed for other types of concretes (see Fig. 9). In the literature, researchers have also reported similar behaviour $[2,20]$. This strength reduction can be explained by the establishment of the hygral gradient within the heated specimen, as well as the appearance of supplementary stresses. Another possible explanation is the reduction of the cohesive forces between the C-S-H gel layers. When water adsorbed on the layers expands (thermal expansion of water coefficient: $\left.\alpha_{T}=70 \cdot 10^{-6}\right)$, the distance between the layers also grows, causing the reduction of the Van der Waals forces. Knowing that compressive strength is related to shear stresses, the weaker liaisons between hydrates can cause micro-defects to occur, thus facilitating sliding. Another possible explanation of the material's weakness in the temperature range when water evaporates is the build-up of internal pore pressure, which induces significant internal stresses exerted on the solid skeleton. The role of water in strength reduction at $120^{\circ} \mathrm{C}$ is incontestable. By drying the samples, this local weakening can be successfully eliminated [9].
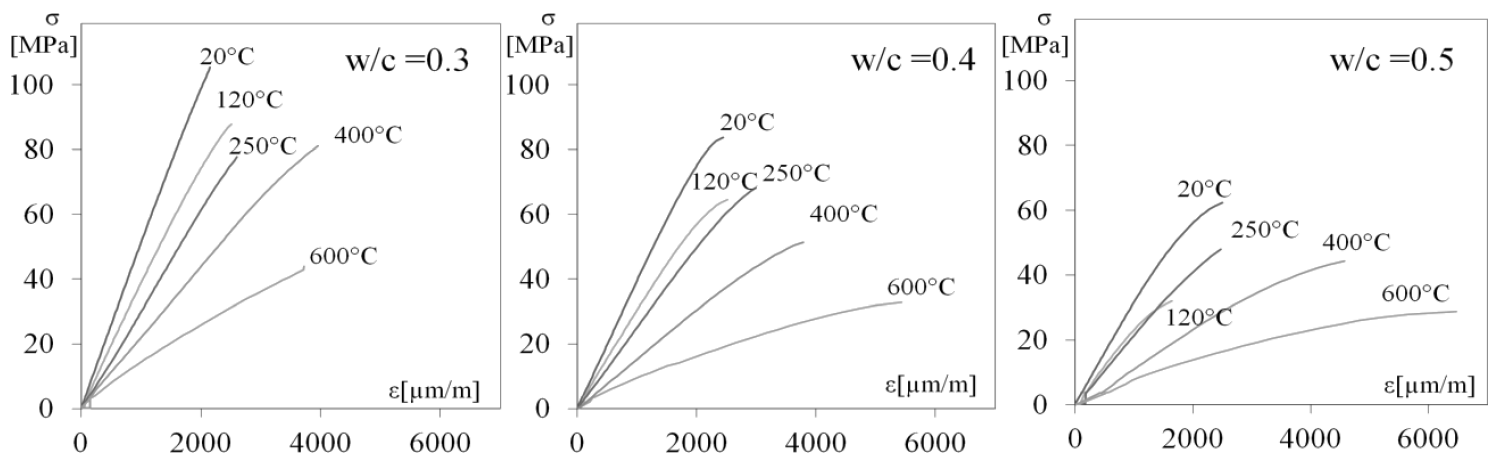

Fig. 10. The $\sigma-\varepsilon$ diagrams for concretes with w/c ratio of $0.3,0.4$, and 0.5 , obtained at temperature of $120^{\circ} \mathrm{C}, 250^{\circ} \mathrm{C}, 400^{\circ} \mathrm{C}, 600^{\circ} \mathrm{C}$ (tested "hot") 


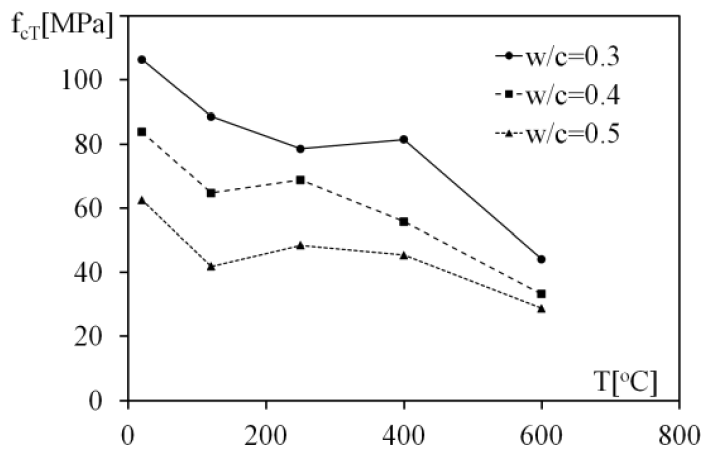

Fig. 11. Changes in compressive strength against temperature, obtained for concretes based on calcareous aggregate with diversified water-cement ratio (tested "hot")

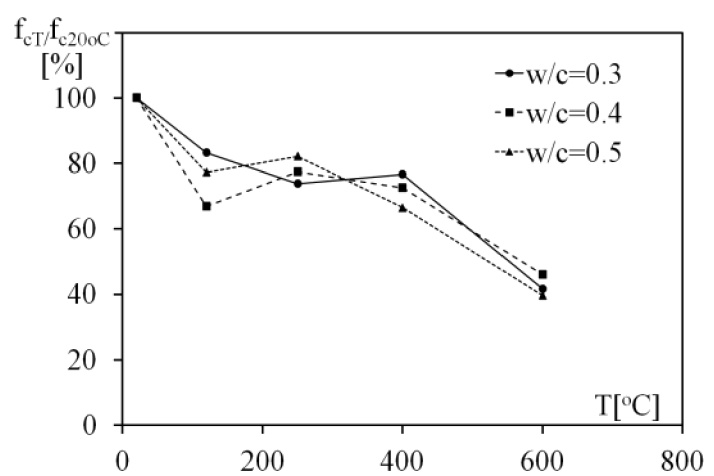

Fig. 12. Changes in relative compressive strength against temperature, obtained for concretes based on calcareous aggregate with diversified water-cement ratio (tested "hot")

In phase II, between $120^{\circ} \mathrm{C}$ and $250^{\circ} \mathrm{C}$, we observe compressive strength values to be higher than those exhibited by samples tested at $120^{\circ} \mathrm{C}$. This apparent increase may be due to water evaporation from the material, as well as to the reduction of the hygral gradient and internal pore pressures. For concrete with a lower water cement ratio $\mathrm{w} / \mathrm{c}=0.3$, the phase of compressive strength recovery seems to be delayed. It is only around $400^{\circ} \mathrm{C}$ that an increase in strength of concrete is observed. This can be explained by the lower permeability of these concretes, as they have a more compact structure that effectively prevents water movement. As a result, the departure of the water is slowed, resulting in a delayed increase in strength. The recovery of strength seems to be dependent on the duration of the maximum temperature plateau [9]. It was observed that by increasing the time of plateau, more water is removed from material, resulting in increased strength.

A progressive reduction of compressive strength is observed in phase III. This descending branch starts when the heating temperature exceeds $250^{\circ} \mathrm{C}$, for concretes with higher water cement ratio $(\mathrm{w} / \mathrm{c}=0.4$ and 0.5$)$, and $400^{\circ} \mathrm{C}$ for concrete with lower $\mathrm{w} / \mathrm{c}=0.3$. The progressive, quasi-linear strength decrease results from portlandite decomposition, C-S-H gel dehydration, and due to the mismatch of deformations between the aggregates, which expand, and cement paste, which itself undergoes shrinkage.

In this research, the modulus of elasticity was determined as the tangent of the inclination angle of $\sigma-\varepsilon$ curves (Fig. 10) at the point corresponding to $1 / 3$ of the ultimate stress. The values of the modulus of elasticity as a function of temperature of concretes are presented in. The modulus of elasticity of heated concretes decreases in a similar way for all watercement ratios. The relative values of modulus of elasticity seem to be independent of the water-cement ratio (see Figs. 13 and 14 [19]). For all three concretes the percentage drop in $\mathrm{E}$ value can be considered as quasi-identical. The increase in temperature generally leads to a consecutive fall in the modulus of elasticity value. However, the elasticity values depend to a large extent on whether the concrete is loaded during heating. It was reported that when constant loading of $20 \%$ of $\mathrm{f}_{c}$ is applied during heating, E may remain unchanged even up to $600^{\circ} \mathrm{C}[1,2]$.

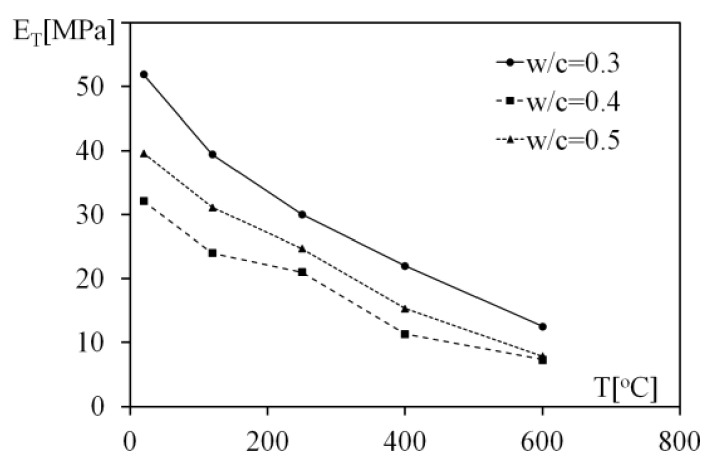

Fig. 13. Changes of modulus of elasticity against temperature, obtained for concretes based on calcareous aggregate with diversified water-cement ratio (tested "hot")

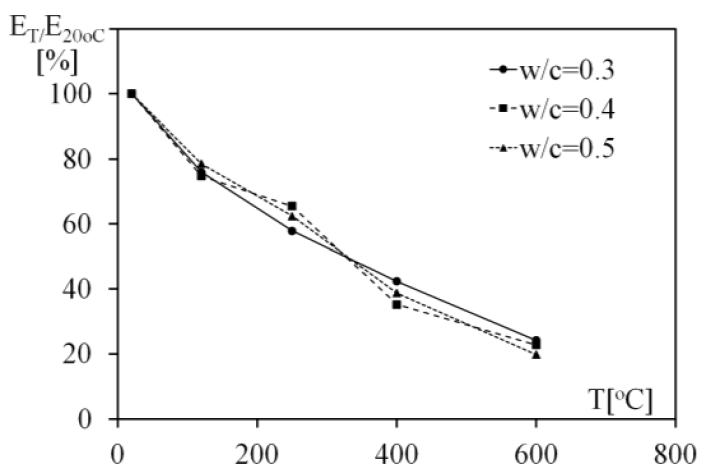

Fig. 14. Changes of relative modulus of elasticity against temperature, obtained for concretes based on calcareous aggregate with diversified water-cement ratio (tested "hot")

3.4. Tensile strength changes. The number of publications presenting the results of tensile strength $\left(f_{t}\right)$ changes caused by heating restrained. This is as a result of the technical difficulties encountered when testing concrete in direct tension at "hot" stage. Most of the $f_{t}$ results found in the literature were obtained after having cooled down the material. However, the residual values of $f_{t}$ were found - similar to compressive strength - to be lower than those obtained in a "hot" stage [21]. The relative values of tensile strength, obtained using various techniques such as by splitting [22], "hot" tested direct tension, and direct tension after cooling down the specimens [23], gradually decrease with the heating temperature. Analyzing changes in concrete tensile strength as a function 
of temperature is very important from the point of view of understanding the spalling, as this type of destruction occurs when internal stresses generated by steam pressure and thermal strains exceed the value of concrete tensile strength.

\section{Explosive spalling of concrete}

Recently, severe cases of explosive spalling have occurred in tunnel fires (Channel Tunnel - 1996, Mont Blanc Tunnel 1999, Gotthard Tunnel - 2001), causing casualties and important financial losses. Spalling results in loss of section and reduction in the load bearing capacity of an element. There are different types of high temperature concrete spalling. These range from complete destruction, through the explosive loosening of larger or smaller pieces of concrete that have thickness ranging from a few millimetres to a few centimetres. In all cases spalling lead to reinforcement steel exposition, which is sensitive to high temperature. The spalling of concrete is one of the more interesting phenomenon occurring in conditions of fire. The literature broadly describes it, both from the experimental [17, 24-26] and the theoretical side, on the bases of various mathematical models of this effect $[27,28]$. The main factors causing spalling of concrete include: reduced cement matrix porosity and the use of pozzolana additives [29, 30], water content in material [29, 30] and condition of stresses brought about by the presence of mechanical load and gradient of temperature. The first attempt of spalling mechanism description may be found in Harmaty [26]. When, during heating, water is transported into cooler zones the formation of a fully saturated layer of concrete occurs. This zone is called moisture clog and it is characterized by low permeability and act as an impermeable barrier for gases (see Fig. 15). In parallel, the temperature rise changes the water into steam, which cannot escape due to water clog presence. This results in internal pressure build-up [24, 27]. The internal pore pressure seems to be an important factor leading to the concrete spalling behaviour - this pressure has been successfully evaluated. As expected, the higher values of internal pore pressures were observed in HPCs due to their dense structure and low permeability [17, 24, 26]. Moisture clog in the heated concrete element may also be the place where, due to local weakness of material, spalling may commence. The presence of water evidently adds up to the probability of the occurrence of the spalling phenomenon. For this reason, the limit on the moisture content of concrete is imposed on some codes and recommendations. In the literature, the limit of $3.0 \%$ for conventional vibrated concrete, and for high performance concrete $2.5 \%$, can be found [30]. However, there are some experimental data available where spalling of concrete even with low moisture content was observed [31] indicating that a fixed limit on moisture content does not ensure concrete safety with respect to spalling.

The other explanation for spalling phenomenon, was presented by Bazant [32]. According to this theory, spalling results from brittle fracture and delamination buckling caused by compressive biaxial thermal stresses parallel to the heated surface. It was also pointed out [32], that the internal pressure build - up cannot be the only reason for spalling occurrence. When a crack, produced by pore pressure, starts to open the internal pore pressure immediately drops [17]. Thus, it has been concluded that the pore pressure can only act as a trigger for the spalling phenomenon. Once the pore pressure has triggered the crack, its growth and the resulting explosive spalling depend on the thermal stresses. Therefore, this complex phenomenon still remains difficult to understand. In addition, the prediction of the spalling sensitivity of a concrete is not yet satisfactory realized [33].
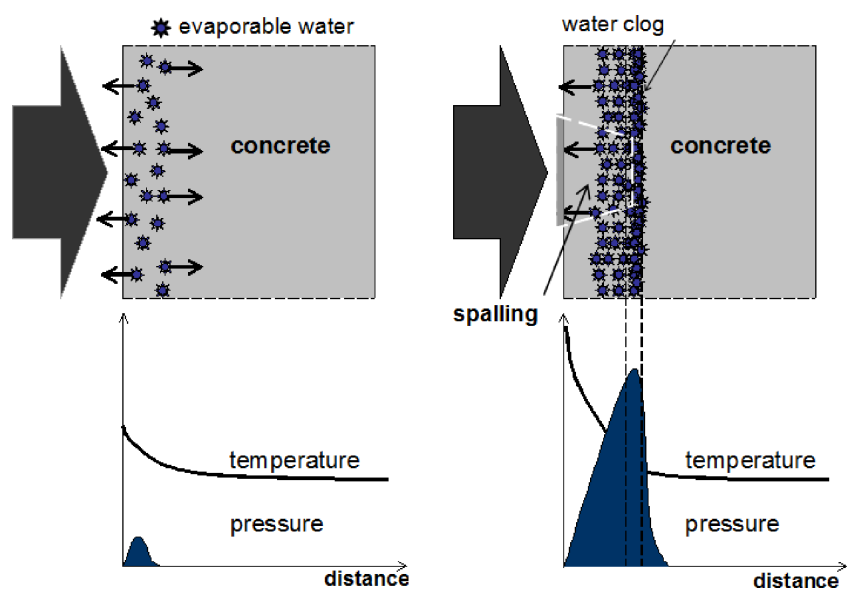

Fig. 15. Water clog and internal pore pressure formation within heated concrete element

4.1. Measures to reduce or prevent spalling. Nowadays, application of insulation boards, cladding panels or sprayed materials are used in order to limit spalling phenomenon occurrence in fire conditions [1]. However, one of the most effective methods that allows for the reduction of this type of damage is to create a network of pores in the material, allowing steam generated during heating to evacuate. A technological solution to this problem is to incorporate polypropylene fibres in the material at the component mixing stage. These fibres melt at approximately $170^{\circ} \mathrm{C}$, and leave a network of open pores, which make steam evacuation easier, thus contributing to the reduction of internal pore pressure [25].

Completed tests confirm the effectiveness of adding polypropylene fibres to increase the transport properties of heated material [34]. In order to determine which length of fibres, used in which minimum amount, permits the development of a connected network of pores seven types of concrete has been tested. The concrete composition has been modified by the addition of fibrillated polypropylene fibres (PP). The study was carried out using concretes made from basalt aggregate and CEM I 52.5R cement. The quantitative and qualitative composition of all HPCs examined was the same, with the exception of the amounts and lengths of the polypropylene fibres used. Fibrillated polypropylene fibres (melting temperature of $163^{\circ} \mathrm{C}$ ) with lengths of 6,12 and $19 \mathrm{~mm}$, and in amounts of $0,0.9$, and $1.8 \mathrm{~kg} / \mathrm{m}^{3}$ were used for the purposes of the research. Cylindrical samples with a diameter of $150 \mathrm{~mm}$ and $50 \mathrm{~mm}$ high were used for measuring gas permeability and surface water absorbability. Both the amount 
and length of polypropylene fibres added had an impact on the magnitude of changes in residual permeability caused by HPC heating. The greatest increase in the residual permeability of heated concretes can be observed in samples in which $1.8 \mathrm{~kg} / \mathrm{m}^{3}$ of 12 or $19 \mathrm{~mm}$ long fibres have been added (Fig. 16). The addition of polypropylene fibres to HPCs heated to temperature ranging from $160^{\circ} \mathrm{C}$ to $200^{\circ} \mathrm{C}$ also affected in a significant way the effective porosity of those concretes, an effect which was confirmed by measurements of changes in surface water absorbability over time. Research results confirmed the beneficial effect of PP fibres on increasing the permeability of high performance concretes, thus reducing the risk of spalling behaviour in real fires.

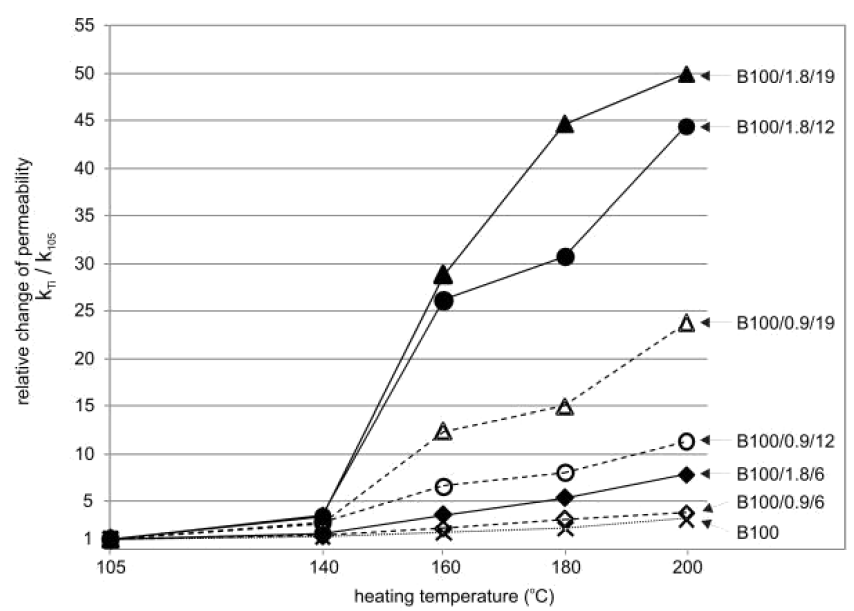

Fig. 16. Relative change of permeability in HPC (B100 according to the authors nomenclature) with and without polypropylene fibres as a function of temperature

\section{Concluding remarks}

This paper presents the results of the investigation of the cement concrete behaviour at a high temperature. It has been shown that the colour change of heated concrete might be the first indication of the potential deterioration of concrete due to heating. The most common way to evaluate this deterioration is to expose the material to a high temperature and test the material in compression and/or tension. Changes in the mechanical properties of concrete caused by heating have been presented in this paper. Tested "hot" mechanical properties, including stress-strain relationship, compressive strength, and modulus of elasticity, decline with the increase of temperature. The possible explanations of the observed gradual decrease of mechanical properties have been discussed in detail. Moreover, the important role of water was put forward, both in the context of the changes of concrete properties as well as in the occurrence of the spalling phenomenon. It has also been revealed that water also plays an important role in a transient thermal strain development. By drying material, the extent of the phenomenon is significantly reduced, or even eliminated, at up to $400^{\circ} \mathrm{C}$. Above this temperature, the mismatch of thermal deformations between the aggregates, which expand, and cement paste, which undergoes shrinkage, prevails and results in the development of cracks. Significant cracking continues, thus altering the material mechanical properties.

Acknowledgements. The selected results and paper preparation were supported with the funds of the National Science Centre within the framework of the N N506 045040 research project. Part of the tests results presented in this paper were obtained with a device developed at the Centre Scientifique et Technique du Bâtiment (CSTB) in France during the PhD research project of the author. Specials thanks are given to Pierre Pimienta from CSTB for his scientific assistance at the research stage. The author would like also to thank Professor Jacek Śliwiński from Cracow University of Technology for his invaluable comments to this paper.

\section{REFERENCES}

[1] Fire Design of Concrete Structures - Materials, Structures and Modelling, Bulletin 38, Fédération Internationale du Béton, p. 97, Lausanne, 2007.

[2] G.A. Khoury, "Compressive strength of concrete at high temperatures : a reassessment", Magazine of Concrete Research 44 (161), 291-309 (1992).

[3] EN 1992-1-2: Eurocode 2 - Design of Concrete Structures. Part 1.2: General Rules - Structural Fire Design, p. 97, December, 2004.

[4] R.F. Feldman and P.J. Sereda, "A model for hydrated Portland cement paste as deduced from sorption-length change and mechanical properties", Materials and Structures 1, 509-519 (1968).

[5] J. Piasta, "Heat deformation of cement phases and microstructure of cement paste", Materials and Structures 17 (102) 415420 (1989).

[6] G. Verbeck and L.E. Copeland, "Some physical and chemical aspects of high pressure steam curing", Menzel Symposium on High Pressure Steam Curing ACI SP-32, 1-131 (1972).

[7] M. Castellote, C. Alonso, C. Andrade, X. Turrillasa, and J. Campoc, "Composition and microstructural changes of cement pastes upon heating, as studied by neutron diffraction", Cement and Concrete Research 34, 1633-1644 (2004).

[8] G.A. Khoury, G.P.E. Sullivan, and B.N. Grainger, "Strain of concrete during first heating to $600^{\circ} \mathrm{C}$ under load", Magazine of Concrete Research 37 (133) 195-215 (1985

[9] I. Hager, "Behaviour of high performance concretes at high temperature - evolution of mechanical properties", PhD Thesis, Ecole Nationale des Ponts et Chaussées, Champs-sur-Marne, 2004, (in French).

[10] N.R. Short, J.A. Purkiss, and S.E. Guise, "Assessment of fire damaged concrete using color image analysis", Construction and Building Materials 15, 9-15 (2001).

[11] M. Colombo and R. Felicetti, "New NDT techniques for the assessment of fire-damaged concrete structures", Fire Safety J. 42 (6-7), 461-472 (2007).

[12] I. Hager, "Colour change in heated concrete", Fire Technology 49, CD-ROM (2013).

[13] U. Diederichs, U.M. Jumppanen, and V. Pentalla, "Behaviour of high strength concrete at elevated temperature", in Report 92, Helsinki University of Technology, Helsinki, 1989.

[14] RILEM, Recommandations Part 6 - "Thermal strain", Materials and Structures, Supplément 1, 17-21 (1997).

[15] I. Hager and P. Pimienta, "Transient thermal strains of high performance concretes", Key note paper, Concreep 7 Int. Conf. 
on Creep, Shrinkage and Durability of Concrete and Concrete Structures 12-14, CD-ROM (2005).

[16] J.C. Mindeguia, P. Pimienta, I. Hager, C. La Borderie, and H. Carré, "Experimental study of transient thermal strain and creep of an ordinary concrete at high temperatures", Proc. 4th International Workshop Structures in Fire (SIF'2006) II, 697708 (2006).

[17] J.C. Mindeguia, "Contribution expérimentale à la compréhension du risqué d'instabilité thermique des bétons", $P h D$ Thesis, Université de Pau et des Pays de l'Adour, Pau, 2009, (in French).

[18] I. Hager and P. Pimienta, "Impact of the polypropylene fibres on the mechanical properties of HPC concrete", Proc. Sixth Rilem Symposium on Fibre Reinforced Concrete (FRC) BEFIB, 20-22 (2004).

[19] I. Hager and P. Pimienta, "Mechanical properties of HPC at high temperatures", Proc. Int. Workshop fib Task Group, Fire Design of Concrete Structures: What now? What next? 4.3, 95-100 (2004).

[20] C. Castillo and A.J. Durrani, "Effect of transient high temperature on high-strength concrete", ACI Materials J. 1, 47-53 (1990).

[21] S. Thelandersson, Effect of High Temperatures on Tensile Strength of Concrete, p. 27, Lund Institute of Technology, Lund, 1971.

[22] A. Noumowe, P. Clasteres, G. Debicki, and M. Bolvin, "Effects of high temperature on high performance concrete $\left(70^{\circ} \mathrm{C}-\right.$ $600^{\circ} \mathrm{C}$ ) - strength and porosity", Third CANMET/ACI Int. Conf. 1, CD-ROM (1994).

[23] R. Felicetti R., P.G. Gambarova, MP.N. Sora, and G.A. Khoury, "Mechanical behaviour of HPC and UHPC in direct tension at high temperature and after cooling", 5th RILEM Symp. FibreReinforced Concretes (FRC) - BEFIB' 2000, 749-760 (2000).

[24] P. Kalifa, F.D. Menneteau, and D. Quenard, "Spalling and pore pressure in HPC at high temperature", Cement and Concrete Research 1, 1915-1927 (2000).
[25] P. Kalifa, G. Chéné, and C. Gallé, "High-temperature behaviour of HPC with polypropylene fibres: From spalling to microstructure", Cement and Concrete Research 31 (10), 14871499 (2001).

[26] T.Z. Harmathy, "Moisture in materials in relation to fire test", ASTM, Special Technical Publication 385, 74-95 (1964).

[27] Z.P. Bazant, "Analysis of pore pressure, thermal stresses and fracture in rapidly heated concrete", Int. Workshop on Fire Performance of High Strength Concrete 13-14, CD-ROM (1997).

[28] D. Gawin, and B.A. Schrefler, "Thermo-hydro-mechanical analysis of partially saturated porous materials", Eng. Computations 13 (7), 113-143 (1996).

[29] K. Hertz, Heat-induced Explosion of Dense Concretes. Report No 166, Technical University of Denmark, Denmark, 1998.

[30] K. Hertz, "Limits of spalling of fire exposed concrete", Fire Safety J. 38, 103-116 (2003).

[31] Z. Zheng, "Experimental study on concrete spalling in prestressed slabs subjected to fire", Fire Safety J. 45, 283-297 (2010).

[32] Z.P. Bazant, "Concrete creep at high temperature and its interaction with fracture: recent progress", Concreep 7 Int.l Conf. on Creep, Shrinkage and Durability of Concrete and Concrete Structures 1, 449-460 (2005).

[33] L. Boström and R. Jansson, "The age effect on fire spalling of concrete", 2nd Int. RILEM Workshop on Concrete Spalling due to Fire Exposure 1, 33-41 (2011).

[34] I. Hager and T. Tracz, "The impact of the amount and length of fibrillated polypropylene fibers on the properties of HPC exposed to high temperature", Archives of Civil Eng. 1, 57-68 (2010).

[35] R. Jansson, Liquid/steam pressure measurement inside concrete exposed to fire, Proceedings from the 4th international workshop Structures in Fire, Aveiro, Portugal, 2006, pp. 747756. 